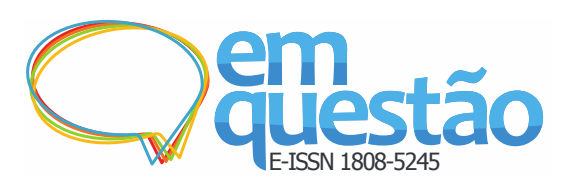

\title{
Os fundamentos da interdisciplinaridade no Campo da Comunicação: uma análise a partir dos artigos da Compós e da Intercom
}

\author{
João de Melo Maricato \\ Doutor; Universidade de Brasília, Brasília, DF, Brasil; \\ jmmaricato@gmail.com \\ Filipe Reis Dias de Jesus \\ Mestrando; Universidade Federal de Goiás, Goiânia, GO, Brasil; \\ filipe.reis17@gmail.com
}

\begin{abstract}
Resumo: São recorrentes as pesquisas com temática interdisciplinar no Campo da Comunicação, porém pouco se conhece os aportes teóricos utilizados para a sua fundamentação. Com base nos artigos publicados nos anais da Compós e da Intercom, entre os anos de 2005 e 2015, e recorrendo-se ao método bibliométrico de análise de citações, a presente pesquisa objetivou identificar os pilares teóricos da interdisciplinaridade no Campo da Comunicação brasileira. Dentre os principais resultados destaca-se, a partir dos autores citados, que os fundamentos teóricos sobre a interdisciplinaridade do Campo da Comunicação são restritos, principalmente nos textos da Compós. Constatou-se que a autoria dos textos que fundamentam o discurso da interdisciplinaridade nos artigos da Compós é predominantemente restrita a autores vinculados a uma única universidade brasileira e a textos de autores do próprio Campo da Comunicação. Não foram encontradas fortes influências, medidas pelas citações, para textos clássicos do campo da filosofia, educação, sociologia, etc. Nos artigos da Intercom, diferentemente, identificou-se fundamentação sobre interdisciplinaridade de outros campos e outros autores nacionais e internacionais, no entanto, ainda de maneira restrita. Ressalta-se a importância de maior mobilização de autores para melhor fundamentação teórica nos estudos da Comunicação, quer sejam na temática interdisciplinar ou contra interdisciplinar, pois constatou-se que em ambos os casos a fundamentação dos discursos aponta fragilidades e pouca amplitude de teorias.
\end{abstract}

Palavras-chave: Campo da Comunicação. Interdisciplinaridade. Bibliometria. Compós. Intercom. 


\section{Introdução}

Uma das características recorrentes nas produções científicas do Campo da Comunicação é a discussão sobre a questão da interdisciplinaridade. Independentemente das visões que defendem ou são contrárias à interdisciplinaridade do campo comunicacional, são necessárias bases de literatura sobre interdisciplinaridade para fundamentar seus discursos. Nessa perspectiva, Signates (2012) é um dos que se arriscam a dizer que a Comunicação é um dos campos chamados interdisciplinares, assim como a ecologia.

Para Martin-Barbero (2009) os estudos em Comunicação são claramente interdisciplinares, e isso não significa um antidisciplinarismo, muito menos uma simples soma de resultados de disciplinas. Assim, considera-se que refletir sobre os fundamentos da interdisciplinaridade no Campo da Comunicação é de grande importância para compreender como esta tem se constituído cientificamente.

As ciências que surgiram Pós-Segunda Guerra Mundial - como a Comunicação - são reconhecidas pelo caráter de se relacionarem com outras ciências. Para Morin, "o progresso dos conhecimentos especializados que não se podem comunicar uns com os outros provoca a regressão do conhecimento geral; as ideias gerais que restam são absolutamente ocas e abstratas." (MORIN, 2014, p. 99). Diante desse cenário, pesquisadores têm buscado na interdisciplinaridade aportes para lidar com as complexidades das ciências e com os problemas causados pela especialização exagerada. Compreender essas relações tem sido um desafio necessário para a compreensão e estruturação de campos científicos, bem como para fornecer insumos para estimular e fortalecer contribuições entre as áreas.

Esta pesquisa tem como objetivo principal identificar as influências teóricas que fundamentam os debates sobre interdisciplinaridade no Campo da Comunicação no contexto brasileiro. Para isso, realiza-se a análise de citações dos trabalhos que versam sobre interdisciplinaridade no campo. Tal abordagem foi utilizada em pesquisas similares em outros campos, como, por exemplo, na Ciência da Informação (CHALHUB; BENCHIMOL; GUERRA, 2013). No entanto, não foram 
encontradas na literatura abordagens que buscassem identificar influências e fundamentos teóricos sobre o discurso interdisciplinar no campo comunicacional.

Delimitou-se como objetivos específicos: (1) discutir o movimento da interdisciplinaridade; (2) apresentar o Campo da Comunicação com foco nas discussões de seu estatuto disciplinar, inter ou transdisciplinar; (3) identificar os trabalhos que se engajaram em debater a temática da interdisciplinaridade apresentados nos dois eventos mais importantes do Campo da Comunicação no Brasil: o da Associação Nacional dos Programas de Pós-Graduação em Comunicação (Compós) e o da Sociedade Brasileira de Estudos Interdisciplinares da Comunicação (Intercom Nacional); e (4) analisar as citações explicitamente utilizadas para fundamentar teoricamente o discurso interdisciplinar no Campo da Comunicação.

\section{Interdisciplinaridade}

A fragmentação do saber foi um processo necessário no desenvolvimento da ciência. Contudo, apesar da necessidade da especialização, Morin (2003) entende que esse modelo de organização pode ser arriscado quando se atinge hiperespecialização. A interdisciplinaridade emerge, em grande medida, para se interpor à hiperespecialização científica.

Segundo Sills (1986), a palavra interdisciplinaridade apareceu pela primeira vez em 1937, sendo usada pelo sociólogo Louiz Wirtz. Entretanto, antes disso a Academia de Ciências dos Estados Unidos havia empregado a expressão cruzamento de disciplinas, e o Instituto de Relações Humanas da Universidade de Yale defendia uma "demolição das fronteiras disciplinares." (SILLS, 1986 apud CASANOVA, 2006, p. 19).

Para Japiassú (1976) a interdisciplinaridade tem dupla origem, uma interna e outra externa. A primeira teve como característica essencial o remanejamento de sistemas das ciências, ou seja, novas formas de organizar os saberes científicos. A segunda se caracterizou pela mobilização cada vez mais extensa dos saberes convergindo em vista da ação. 
Após a Segunda Guerra Mundial surgiram ciências que não são facilmente classificadas como disciplinares. Pombo (2003) aponta o aparecimento de três grandes novos tipos de formações disciplinares: (1) ciências de fronteiras; (2) interdisciplinas; e (3) interciências. Segundo a autora, interdisciplinas são novas disciplinas que surgem do cruzamento das disciplinas científicas com o campo industrial e organizacional. Alguns exemplos seriam relações internacionais e organizacionais, sociologia das organizações e psicologia industrial. Nesse sentido, partimos da perspectiva de que a Ciência da Comunicação nasce nesse contexto de campos com dificuldades de delimitações disciplinares, pois seus problemas exigem mais de uma disciplina para analisá-los, compreendê-los e resolvê-los.

\subsection{Campo da Comunicação}

A palavra campo cresceu com numerosas raízes em diversos idiomas. Sua semente foi lançada no idioma indo-europeu com o termo kamp. Já nesse tempo, kampos significava canto de terreno ou pequena baía arredondada. No latim, a palavra campus se estabeleceu significativamente como "área cercada por bosques ou colinas" e, com o tempo, seu significado mudou para "área plana para plantio". Ou seja, passa a designar os hábitos e o modo de viver de pessoas que se dedicavam à agricultura e à criação de animais. As raízes do termo "campo" cresceram para outros contextos, como, por exemplo, o militar. O termo campeão se origina na palavra campo, designando, inicialmente, guerreiro que lutava no campo. Posteriormente, passa a significar vencedor. Do termo campo também saíram outros termos, como: campanha, campânula, acampar, campesino, campear, campeira, campus, etc. (LIDA..., 2016).

Percebe-se, ao longo da sua evolução, que o termo campo passa a designar arena, espaço de batalha, terreno que propicia discussão, entre outros. Numa perspectiva social, campo designa "objeto de luta tanto em sua representação quanto em sua realidade". (BOURDIEU, 2004, p. 29). Portanto, o campo científico "é um 
campo de forças e um campo de lutas para conservar ou transformar esse campo de forças.” (BOURDIEU, 2004, p. 22-23).

No século II a.C., Aristóteles auxilia na fundamentação do Campo da Comunicação, associando-o com os estudos da retórica. Foi o primeiro a dividir o processo de comunicação em três elementos básicos: o locutor, o discurso e o ouvinte. Temer e Nery (2009) afirmam que graças às bases aristotélicas, a comunicação deixou de ser vista como neutra, passando a ser reconhecida como uma ação que provoca mudanças e é carregada de objetivos. Desse modo, é possível entender a comunicação como processo de interação que se justifica como relação cultural entre os sujeitos.

Importa destacar que a palavra comunicar vem do latim, comunicare, que significa tornar comum, partilhar, repartir, associar, trocar opiniões, conferenciar (RABAÇA; BARBOSA, 1987). Porém, o conceito de comunicação pode se apresentar em diferentes enfoques e escolas. Sendo assim, é quase incongruente falar em “definição de comunicação" tendo em vista a complexidade semântica do termo comunicação. Mattelart e Mattelart dizem que "a noção de comunicação recobre uma multiplicidade de sentidos" (MATTELART; MATTELART, 1999, p. 9). Nesse mesmo sentido, Saracevic (1996, p. 52, grifo do autor) afirma que "Se existe alguma palavra que tenha mais conotações, maior uso em muitos e diferenciados contextos e maiores motivos para confusão do que informação, essa palavra é comunicação.” Em meio a essas multiplicidades, norteia-se o olhar para comunicação numa perspectiva social. Como afirma Silva (2004), apoiando-se no sociólogo da comunicação Michel Maffesoli ${ }^{1}$, a comunicação é um laço social.

A partir da concepção multifacetada do conceito de comunicação, emerge o Campo da Comunicação para compreender, entre outras coisas, a chamada comunicação de massa, que é o pharmacon $^{2}$, que fomentou críticas e apoios no começo do século XX. Além deste texto não apresentar uma visão maniqueísta do assunto, ele também não tem como objetivo aprofundar essa discussão.

Destaca-se que o Campo da Comunicação surge como ciência social aplicada, evoluindo a partir da articulação entre saberes teóricos e práticas 
pedagógicas. Nas universidades, nasceu o desejo de adaptar os cursos ao novo campo e à rápida expansão de novas profissões. Do ponto de vista intelectual, uma das origens do campo é a interrogação antropológica sobre a redefinição da cultura com as diferentes maneiras de comunicar, com base nas pesquisas de Lévi-Strauss, Barthes ou Jakobson ${ }^{3}$ (BOUGNOUX, 1999).

Desde então, a comunicação tem se firmado como um domínio de investigação. Temer e Nery denominam Comunicação Social como:

Um campo de estudo e/ou de reflexões teóricas e práticas sobre o desenvolvimento, intercâmbio e consequências do processo de transmissão e recepção de mensagens mediadas tecnologicamente na sociedade. (TEMER; NERY, 2009, p. 17).

De forma esquemática, Martino (2006) apresenta as fases do desenvolvimento do pensamento comunicacional: (1) Pré-científico: período anterior a 1920, marcado pelo surgimento dos modernos meios de comunicação até meados do século XVIII; (2) Flerte com a ciência: entre 1920 e 1930, com análises e teorias científicas para avaliar os meios de comunicação; (3) Científico: entre 1940 e 1950. Com a Segunda Guerra Mundial, surge a necessidade de tratamento da informação. O exército estadunidense investe em pesquisas para desenvolver estratégias de uso dos meios de comunicação. Esse período é marcado também pela contribuição de outras disciplinas, como psicologia, sociologia, ciências políticas, linguística, etc.; (4) Cético: entre as décadas de 1960 e 1980, é marcado por debates epistemológicos e sistematização teórica. A ciência da comunicação é percebida como interdisciplinar; (5) Interdisciplinar: a partir dos anos 1980, a comunicação é vista como interdisciplinar. Isso passa, aos poucos, a influenciar as pesquisas na área.

Lopes (2000-2001) afirma que os estudos de comunicação no Brasil vivem um paradoxo entre a busca pela especialização institucional do campo em tempos do aumento da fragmentação e de trabalho de interfaces. "A sua institucionalização como campo acadêmico é concomitante a uma progressiva afirmação de seu estatuto transdisciplinar", diz Lopes (2000-2001, p. 56).

A singularidade do Campo da Comunicação vai estabelecer sua constituição na arena de lutas internas e externas. Para Lopes, o Campo da Comunicação se 
define como "Um conjunto de instituições de nível superior destinado ao estudo e ao ensino da comunicação e onde se produza teoria, a pesquisa e a formação universitária das profissões de comunicação" (LOPES, 2000-2001, p. 48).

Tal definição implica que o Campo da Comunicação pode ser identificado em três subcampos: (1) o científico; (2) o educativo; e (3) o profissional. O primeiro resulta da produção de conhecimento através da construção de objetos, teorias e métodos. O segundo se define pelo ensino do saber produzido na comunicação. Já o terceiro se caracteriza pela aplicação do conhecimento da comunicação e estabelecendo veículos variados com o mercado. (LOPES, 2000-2001).

Lopes (2000-2001) afirma que as interfaces do Campo da Comunicação são estabelecidas preferencialmente com as ciências humanas e sociais (filosofia, ética, estética, história, política, economia, sociologia) e com as ciências sociais aplicadas (ciência da informação, administração, educação, direito). Essas relações preferenciais do Campo da Comunicação foram percebidas, empiricamente, pelo estudo de Reis (2014). Ao analisar a formação dos participantes das bancas de doutorado de programas de pós-graduação em Comunicação e Ciência da Informação do Brasil, constatou que a Comunicação conta com a forte participação de pesquisadores das áreas de Ciências Humanas em suas bancas.

Abordando a temática interdisciplinar no Campo da Comunicação, Braga (2011, p. 74) sustenta que "é importante manter a diversidade, mas devendo-se trabalhar contra a dispersão". Antes de toda essa discussão, deve estar o fenômeno comunicativo. Ao analisá-lo, cada ciência e corrente filosófica utilizará sua própria perspectiva, terminologia e conceitos específicos. De maneira semelhante, Marques de Melo (1973) considera que uma dificuldade encontrada no estudo em Comunicação é a sua consolidação. Deve-se buscar essa consolidação do Campo, caso contrário o fenômeno comunicativo será sempre visto sob o prisma de outros campos. Perde-se, assim, a legitimidade para pesar os processos comunicativos sem as amarras da sociologia, filosofia, psicologia, etc. 


\section{Metodologia}

Esta pesquisa se caracteriza como qualitativa e quantitativa, pois, assim como Bicalho (2009), não acredita-se em uma pesquisa em ciências sociais aplicadas com abordagem estritamente quantitativa ou antiquantitativa. Como afirma Minayo e Sanches (1993), as abordagens quantitativa e qualitativa são complementares. Por buscar desenvolver, esclarecer e modificar conceitos e ideias, esta pesquisa pode ser classificada como exploratória (GIL, 1999). A metodologia utilizada é cientométrica, lançando mão da técnica de análise de citação.

Defende-se que a análise de citação, ao representar em grande medida a influência dos citantes com relação aos citados, pode contribuir com o entendimento das influências teóricas. Chalhub, Benchimol e Guerra afirmam que:

Uma citação é uma referência documental que, quando incluída num texto, mostra relações entre o documento citado e o documento citante, em outras palavras, é o empréstimo de uma ideia por escrito. Existem diversos motivos para que autores sejam citados por outros, dentre esses podemos destacar a importância de dar créditos a trabalhos sobre a temática, homenagear os pioneiros em determinado tema, além de criticar e corrigir trabalhos de outros autores ou o próprio. (CHALHUB; BENCHIMOL; GUERRA, 2013, doc. não paginado).

Conforme as autoras Vanz e Caregnato,

[...] a análise de citação possibilita melhor entendimento dos processos de comunicação científica [...], além de identificar a visibilidade de autores e as linhas de pensamento dos membros de determinada comunidade científica. (VANZ; CAREGNATO, 2003, p. 5).

Ainda acrescentam que "os estudos de citação constituem um importante indicador da atividade científica, pois contribuem para entender a estrutura e o desenvolvimento da ciência [...] identificam as regularidades básicas de seu funcionamento." (VANZ; CAREGNATO, 2003, p. 255).

Foram analisados os trabalhos, que são explicitamente relacionados com a discussão da questão da interdisciplinaridade no Campo da Comunicação, publicados nos eventos científicos da Compós e da Intercom (Intercom Nacional). As buscas nas bases de dados foram realizadas sem recorte temporal, sendo encontrados textos sobre interdisciplinaridade entre o período de 2005 e 2015. 
Foram selecionados os artigos que apresentaram os termos interdisciplinaridade, pluridisciplinaridade, multidisciplinaridade, transdisciplinaridade e suas variantes no título. Em seguida foram identificadas as referências citadas relacionadas aos mesmos termos em cada um dos artigos recuperados. Em outras palavras, dentre os artigos publicados nos anais da Compós e da Intercom, foram selecionados aqueles que continham as palavras interdisciplinar/interdisciplinaridade no título. Nestes, foram selecionados os textos referenciados/citados que apresentaram os termos interdisciplinaridade/interdisciplinar no título.

Assim, como consta no Quadro 1, foram recuperados três trabalhos da Compós, com a seguinte distribuição nos anos: 2005 (um) e 2015 (dois). Na Intercom foram selecionados 15 trabalhos, distribuídos nos anos: 2006 (cinco), 2007 (um), 2008 (dois), 2009 (dois), 2011 (dois), 2012 (dois), 2013 (um). Posteriormente, analisaram-se as referências/citações de modo a identificar os autores e os trabalhos citados relacionados à interdisciplinaridade. Desse modo, entende-se que seja possível identificar quais os autores e trabalhos utilizados como base teórica para fundamentar os discursos interdisciplinares do Campo da Comunicação.

Nos 18 artigos, foram identificadas 39 referências citadas (cinco na Compós e 34 na Intercom) com a palavra interdisciplinar/interdisciplinaridade no título. A Figura 1 sintetiza as três principais etapas do processo de levantamento, extração, organização e análise dos dados.

Figura 1 - Processo de levantamento, extração, organização e análise dos dados.
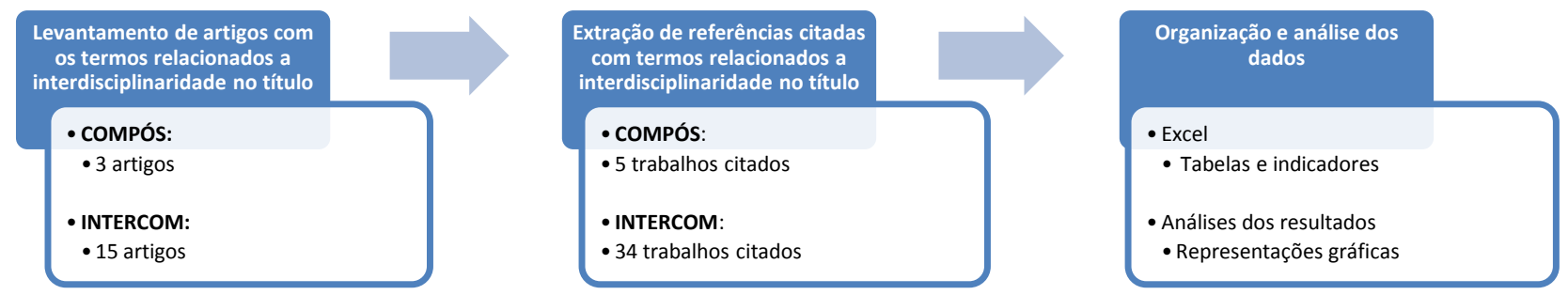

Fonte: Elaborado pelos autores. 


\section{Resultados e discussões}

Sumarizando os resultados de maneira comparativa, foram encontrados três artigos publicados na Compós (17\%) e 15 (83\%) na Intercom relacionados à interdisciplinaridade. Os artigos da Compós citaram seis obras (15\%), e a Intercom, $34(85 \%)$. A quantidade de citações totais realizadas pelos artigos da Compós foi 63 (26\%), e destas, seis $(25 \%)$ se relacionam à interdisciplinaridade. A quantidade total de citações realizadas nos artigos da Intercom foi de $183(74 \%)$, e destas, 18 (75\%) se relacionaram à interdisciplinaridade. Considerando os dados dos dois eventos conjuntamente, observa-se que o número de obras citadas nos trabalhos da Compós e da Intercom totalizaram $246 \mathrm{e}$ as citações de obras relacionadas à interdisciplinaridade totalizaram 24. Ou seja, $10 \%$ das citações se relacionam a trabalhos que versam sobre temas relacionados à interdisciplinaridade.

O Quadro 1 lista os 18 artigos recuperados nos anais da Compós e da Intercom que apresentam o termo interdisciplinar/interdisciplinaridade no título. Desses 18 trabalhos, três foram recuperados nos anais da Compós e 15 nos anais da Intercom. Nota-se que o artigo mais antigo é do ano de 2005, e o mais recente, de 2015. Nos anos 2010 e 2014 não foram publicados trabalhos explicitamente relacionados à temática interdisciplinar nos eventos. Constata-se com isso que o interesse do Campo da Comunicação brasileiro sobre a temática interdisciplinaridade é recente. Salienta-se, porém, que não existe um conjunto de pesquisadores que dominam o debate sobre interdisciplinaridade no contexto do Campo da Comunicação no Brasil (considerando o total de trabalhos publicados na Compós e na Intercom). No entanto, a autora Boaventura, com três trabalhos recuperados, acaba por se destacar nesse cenário.

Quadro 1 - Obras publicadas nos anais da Compós e da Intercom com explícita relação com a temática interdisciplinaridade.

\begin{tabular}{|c|c|c|c|c|}
\hline Autores & Título & Ano & Intercom & Compós \\
\hline $\begin{array}{l}\text { BEHAR, P. A.; LEITE, S. M.; } \\
\text { MAZZOCATO, S. B.; SOUZA, } \\
\text { L. B.; SIQUEIRA, L. G. }\end{array}$ & $\begin{array}{l}\text { A Avaliação do Ambiente Virtual de Aprendizagem } \\
\text { ROODA: Uma Experiência Interdisciplinar na } \\
\text { UFRGS }\end{array}$ & 2006 & $\mathrm{X}$ & \\
\hline BOAVENTURA, K. T. & $\begin{array}{l}\text { Interdisciplinaridade e Comunicação: um } \\
\text { levantamento crítico }\end{array}$ & 2015 & & $\mathrm{X}$ \\
\hline
\end{tabular}




\begin{tabular}{|c|c|c|c|c|}
\hline Autores & Título & Ano & Intercom & Compós \\
\hline BOAVENTURA, K. T. & $\begin{array}{c}\text { Interdisciplinaridade e Comunicação: contribuições e } \\
\text { críticas }\end{array}$ & 2011 & $\bar{X}$ & \\
\hline BOAVENTURA, K. T. & $\begin{array}{c}\text { O que é interdisciplinaridade? Uma questão mal } \\
\text { resolvida para a Comunicação }\end{array}$ & 2012 & $\mathrm{X}$ & \\
\hline DENCKER, A. F. M. & $\begin{array}{l}\text { A pesquisa interdisciplinar e hospitalidade na } \\
\text { formação universitária em turismo }\end{array}$ & 2009 & $\mathrm{X}$ & \\
\hline $\begin{array}{l}\text { CABRAL FILHO, A. V. C.; } \\
\text { LOPES, A. J. F. }\end{array}$ & $\begin{array}{c}\text { A contribuiçãão da Comunicação como espaço } \\
\text { interdisciplinar na afirmação cidadã do trabalho do } \\
\text { Assistente Social }\end{array}$ & 2015 & & $\mathrm{X}$ \\
\hline FLÓRIO, M. & $\begin{array}{l}\text { A linguagem cinematográfica como objeto de estudo } \\
\text { interdisciplinar }\end{array}$ & 2006 & $\mathrm{X}$ & \\
\hline $\begin{array}{l}\text { LEITE, S. M.; BEHAR, P. A.; } \\
\text { BECKER, M. L. }\end{array}$ & $\begin{array}{c}\text { Relações Interdisciplinares na Ação de Projetar } \\
\text { Ambientes Virtuais de Aprendizagem }\end{array}$ & 2009 & $\mathrm{X}$ & \\
\hline $\begin{array}{c}\text { LELO, T. V.; CAMINHAS, L. R. } \\
\text { P. }\end{array}$ & $\begin{array}{l}\text { A ritualização do corpo dissonante nos media: uma } \\
\text { abordagem interdisciplinar dos discursos sobre } \\
\text { celebridades da moda do Fashion Rio } 2011\end{array}$ & 2011 & $\mathrm{X}$ & \\
\hline $\begin{array}{l}\text { LOPES, P. F. C; MAGALHÃES, } \\
\text { A. M. }\end{array}$ & $\begin{array}{c}\text { A Comunicação e um dos seus dilemas: a } \\
\text { interdisciplinaridade }\end{array}$ & 2012 & $\mathrm{X}$ & \\
\hline MARTINEZ, E. S. & $\begin{array}{l}\text { Anotações para uma metodologia da pesquisa } \\
\text { interdisciplinar na crítica dos projetos curatoriais } \\
\text { para a arte na contemporaneidade }\end{array}$ & 2008 & $\mathrm{X}$ & \\
\hline MARTINO, L. C. & $\begin{array}{l}\text { Ceticismo e interdisciplinaridade: paradoxos e } \\
\text { impasses da teoria da comunicação }\end{array}$ & 2005 & & $\mathrm{X}$ \\
\hline $\begin{array}{l}\text { PINZAN, E. J.; ALMEIDA, F. } \\
\text { E.; SUGIYAMA, M. S. G. }\end{array}$ & $\begin{array}{l}\text { Comunicação e Interdisciplinaridade em Educação } \\
\text { de Hospitalidade }\end{array}$ & 2006 & $X$ & \\
\hline PRESAS, P. P.; PRESAS, J. F. & $\begin{array}{c}\text { Publicidade Gráfica ou Design Publicitário? } \\
\text { Um estudo sobre a interdisciplinaridade entre os } \\
\text { cursos de Comunicação Social e Design }\end{array}$ & 2006 & $\mathrm{X}$ & \\
\hline PRESSLER, N. G. S. & $\begin{array}{c}\text { A construção das práticas de comunicação social sob } \\
\text { o ponto de vista da reflexão interdisciplinar: Meio } \\
\text { ambiente, mídia e desenvolvimento sustentável na } \\
\text { Amazônia a partir da década de } 90\end{array}$ & 2006 & $\mathrm{X}$ & \\
\hline $\begin{array}{l}\text { SANTANA, S. A.; FONTANA, } \\
\text { M. }\end{array}$ & $\begin{array}{l}\text { Trabalho Interdisciplinar: Experiência de Ensino em } \\
\text { Publicidade e Propaganda }\end{array}$ & 2007 & $\mathrm{X}$ & \\
\hline SANTOS, A. C.; TONUS, M. & $\begin{array}{l}\text { A interdisciplinaridade em questão: Tecnologias, } \\
\text { Comunicação e Educação na pós-graduação } \\
\text { stricto sensu }\end{array}$ & 2013 & $\mathrm{X}$ & \\
\hline SANTOS, P. D. & $\begin{array}{l}\text { Redes de Colaboração Científica Interdisciplinares: } \\
\text { estudo de caso na Rede Brasileira de Universidades } \\
\text { Federais }\end{array}$ & 2008 & $\mathrm{X}$ & \\
\hline
\end{tabular}

Fonte: Elaborado pelos autores.

A partir dos 18 artigos recuperados nos anais da Intercom e da Compós foram identificadas as referências citadas com o termo interdisciplinar/interdisciplinaridade no título, acreditando ser possível entender que esses textos fundamentam, em grande medida, os discursos de interdisciplinaridade no Campo da Comunicação no Brasil. 
O Gráfico 1 apresenta os autores mais citados na temática interdisciplinaridade, autores que tiveram ao menos duas citações. Nota-se que nos três trabalhos sobre interdisciplinaridade recuperados nos anais da Compós foram identificados seis referenciados/citados na temática interdisciplinaridade. Desses seis textos, Martino foi o mais citado, como pode ser visualizado no Gráfico 1, na cor vermelha. Salienta-se que das 64 obras referenciadas, nos três artigos recuperados dos anais da Compós, apenas seis se inserem explicitamente na temática interdisciplinar.

Gráfico 1 - Principais autores referenciados/citados, com temática interdisciplinar, nos artigos presentes nos anais da Compós e da Intercom na temática interdisciplinar.

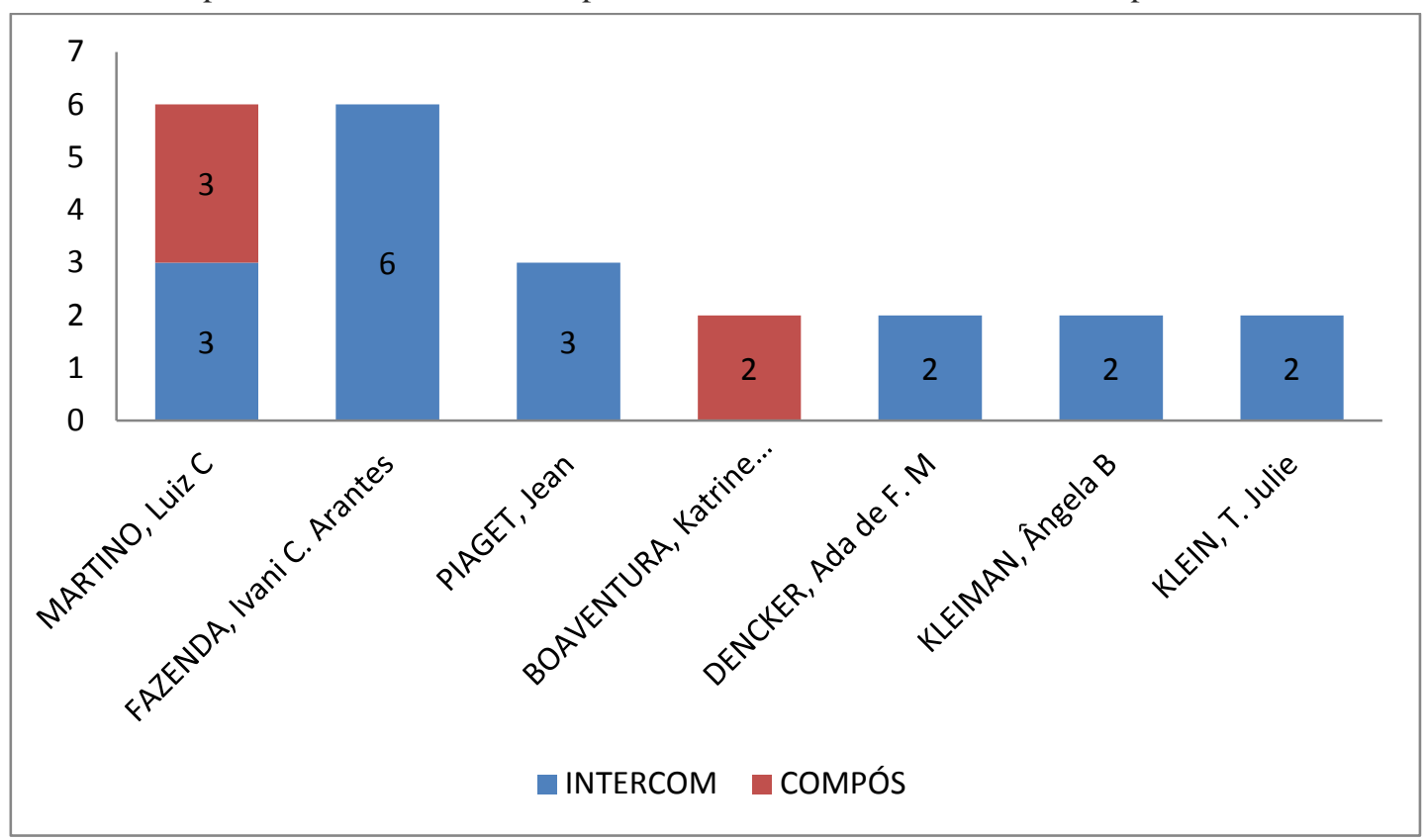

Fonte: Elaborado pelos autores.

No Gráfico 1 são apresentados os autores mais citados nos 15 artigos recuperados nos anais da Intercom. Foram identificadas 18 (de 183) referências citadas relacionadas diretamente com interdisciplinaridade no Campo da Comunicação. Apenas sete autores, com mais de duas citações, são utilizados explicitamente para fundamentar o discurso interdisciplinar no Campo da Comunicação no Brasil. Observa-se que MARTINO e FAZENDA são os autores mais citados na temática; no entanto, foram citados apenas seis vezes cada um. Isso 
remete à possibilidade de o tema interdisciplinaridade não estar sendo fortemente debatido ou ser de pouco interesse do Campo da Comunicação. Nota-se que apenas Martino foi citado nos dois eventos. Assim, constata-se que a citação de fontes e autores sobre interdisciplinaridade nos dois eventos tem baixa e dispersa ocorrência.

O Quadro 2 apresenta autores, obras, anos e quantidades de citações dessas obras na produção da Compós e da Intercom. Percebe-se que das seis obras referenciadas nos trabalhos recuperados dos anais da Compós, três se concentram nos autores BOAVENTURA e MARTINO. Assim, as obras mais citadas pelos autores que publicaram seus artigos na Compós são autocitações, ou seja, as obras que fundamentam a discussão sobre interdisciplinaridade nos artigos desses autores são predominantemente obras produzidas por eles mesmos. Há, portanto, pouca influência explícita de autores de outros campos, como da filosofia, da educação e da sociologia, que têm refletido sobre as questões da interdisciplinaridade há muito tempo. Ressalta-se que tanto para defender quanto para contradizer o movimento da interdisciplinaridade é necessário compreender essa prática, sendo "necessária a busca ou o desvelamento do percurso teórico-pessoal de cada pesquisador que se aventurou a tratar as questões desse tema" (FAZENDA, 2012, p. 13).

Quadro 2 - Obras citadas/referenciadas nos artigos publicados na Compós e na Intercom relacionadas à temática interdisciplinaridade.

\begin{tabular}{|c|c|c|c|c|}
\hline Autor & Título & Ano & $\begin{array}{c}\text { Citações } \\
\text { Intercom }\end{array}$ & $\begin{array}{l}\text { Citações } \\
\text { Compós }\end{array}$ \\
\hline ALVARES, M. R. & $\begin{array}{c}\text { Ensino do Design: A Interdisciplinaridade na } \\
\text { Disciplina de Projeto em Design }\end{array}$ & 2004 & 01 & \\
\hline BARBOSA, A. M. T. B & $\begin{array}{c}\text { A questão da interdisciplinaridade nas escolas de } \\
\text { comunicação }\end{array}$ & 2011 & 01 & \\
\hline BARROS, A. T. & $\begin{array}{l}\text { A natureza interdisciplinar da Comunicação e o novo } \\
\text { cenário da produção de... }\end{array}$ & 2014 & & 01 \\
\hline BERGER, G. & Conditions d'une problématique de l'interdisciplinarité & 1972 & 01 & \\
\hline BOAVENTURA, K. T. & $\begin{array}{c}\text { A Comunicação e a Perspectiva Interdisciplinar: um } \\
\text { mapa de definições, usos e... }\end{array}$ & 2014 & & 01 \\
\hline CAPES & $\begin{array}{c}\begin{array}{c}\text { Documento de Área - Área Interdisciplinar. Brasília: } \\
\text { Capes }\end{array} \\
\end{array}$ & 2009 & 01 & \\
\hline DENCKER, A. F. M. & $\begin{array}{c}\text { Pesquisa e interdisciplinaridade no ensino superior: } \\
\text { uma experiência no curso de turismo }\end{array}$ & 2002 & 02 & \\
\hline FAZENDA, I. & Dicionário em Construção: interdisciplinaridade & 2001 & 01 & \\
\hline FAZENDA, I. & Didática e Interdisciplinaridade & 1998 & & \\
\hline FAZENDA, I. & $\begin{array}{l}\text { Integração e interdisciplinaridade no ensino brasileiro: } \\
\text { efetividade ou ideologia: RE Realidade Educacional }\end{array}$ & 2002 & 01 & \\
\hline FAZENDA, I. & Interdisciplinaridade: História, teoria e pesquisa & 1994 & 01 & \\
\hline
\end{tabular}




\begin{tabular}{|c|c|c|c|c|}
\hline Autor & Título & Ano & $\begin{array}{l}\text { Citações } \\
\text { Intercom }\end{array}$ & \begin{tabular}{|l} 
Citações \\
Compós \\
\end{tabular} \\
\hline FAZENDA, I. & Práticas Interdisciplinares na Escola & 1999 & 01 & \\
\hline FAZENDA, I. & O que é interdisciplinaridade? & 2008 & 01 & \\
\hline GONÇALVES, M. A. S. & $\begin{array}{c}\text { Teoria da ação comunicativa de Habermas: } \\
\text { Possibilidades de... }\end{array}$ & 1999 & 01 & \\
\hline HECKHAUSEN, $\mathrm{H}$. & Discipline et interdisciplinarité & 1972 & 01 & \\
\hline JAPIASSÚ, H & Interdisciplinaridade e patologia do saber & 1976 & 01 & \\
\hline KLEIMAN, A. B. & Leitura e interdisciplinaridade & 1999 & 01 & \\
\hline $\begin{array}{l}\text { KLEIMAN, A. B; } \\
\text { MORAES, S. E. }\end{array}$ & $\begin{array}{l}\text { Leitura e interdisciplinaridade: tecendo redes nos } \\
\text { projetos da escola }\end{array}$ & 1999 & 01 & \\
\hline KLEIN, T. J. & $\begin{array}{c}\text { Crossing boundaries: Knowledge, Disciplinary, and } \\
\text { Interdisciplinary }\end{array}$ & ? & 01 & \\
\hline KLEIN, T. J. & Interdiciplinary: History, Theory \& Practice & 1990 & 01 & \\
\hline LATTUCA, L. R & $\begin{array}{c}\text { Creating Interdisciplinarity: Interdisciplinary, } \\
\text { Research and Teaching }\end{array}$ & 2001 & 01 & \\
\hline LEITE, S. M. & $\begin{array}{l}\text { A interdisciplinaridade na ação de projetar ambientes } \\
\text { virtuais de... }\end{array}$ & 2008 & 01 & \\
\hline LEITE, S. M.; BEHAR, P. & $\begin{array}{c}\text { O desenvolvimento de ambientes virtuais de } \\
\text { aprendizagem por grupos interdisciplinares: a } \\
\text { experiência do Projeto ROODA }\end{array}$ & 2005 & 01 & \\
\hline MARTINO, L. C. & $\begin{array}{l}\text { Ceticismo e Interdisciplinaridade: paradoxos e } \\
\text { impasses da teoria da comunicação }\end{array}$ & 2005 & 01 & 01 \\
\hline MARTINO, L. C. & $\begin{array}{c}\text { As epistemologias contemporâneas e o lugar da } \\
\text { Comunicação }\end{array}$ & 2003 & 01 & \\
\hline MARTINO, L. C & $\begin{array}{c}\text { Interdisciplinaridade e Objeto de Estudo da } \\
\text { Comunicação }\end{array}$ & 2001 & 01 & 01 \\
\hline $\begin{array}{c}\text { MARTINO, L. C; } \\
\text { BOAVENTURA, K. T. }\end{array}$ & $\begin{array}{c}\text { O Mito da Interdisciplinaridade: história e } \\
\text { institucionalização de uma... }\end{array}$ & 2013 & & 01 \\
\hline MORIN, E. & $\begin{array}{c}\text { Sur l'interdisciplinarité. Bulletin Interactif du Centre } \\
\text { International de Recherches et Études } \\
\text { transdisciplinaires }\end{array}$ & 1994 & 01 & \\
\hline NOGUEIRA, N. R. & $\begin{array}{l}\text { Pedagogia dos projetos: uma jornada interdisciplinar } \\
\text { rumo ao desenvolvimento das múltiplas inteligências }\end{array}$ & 2002 & 01 & \\
\hline PIAGET, J. & Epistemologie des rélations interdisciplinaires & 1972 & 01 & \\
\hline PIAGET, J. & "Metodologia das Relações Interdisciplinares" & 2006 & 01 & \\
\hline PIAGET, J. & $\begin{array}{c}\text { Problemas Gerais da Investigação Interdisciplinar e } \\
\text { Mecanismos Comuns }\end{array}$ & 1976 & 01 & \\
\hline POMBO, O. & Interdisciplinaridade: Ambições e Limites & 2004 & 01 & \\
\hline SANTOMÉ, J. T. & Globalização e interdisciplinaridade & 1998 & 01 & \\
\hline SCHMIDT, J. C. & $\begin{array}{l}\text { What is a problem? On problem-oriented } \\
\text { interdisciplinarity }\end{array}$ & 2011 & 01 & 01 \\
\hline SUGIYAMA, M. S. G. & $\begin{array}{l}\text { Formação interdisciplinar em hotelaria: a experiência } \\
\text { do... }\end{array}$ & 2005 & 01 & \\
\hline TEIXEIRA, O. A. & "Interdisciplinaridade: problemas e desafios" & 2004 & 01 & \\
\hline TRINDADE, D. F. & Interdisciplinaridade: Um novo olhar sobre as ciências & 2008 & 01 & \\
\hline \multicolumn{3}{|c|}{ Soma do total de obras citadas: } & 34 & 06 \\
\hline
\end{tabular}

Fonte: Elaborado pelos autores. 
É interessante notar que, com exceção de SCHMIDT, os outros autores referenciados nos artigos recuperados dos anais da Compós são vinculados à Universidade de Brasília (UnB). Luiz C. Martino é professor titular em teorias e epistemologia da Comunicação, reconhecido pela sua produção no Campo da Comunicação, com várias obras sobre epistemologia da Comunicação. Já a autora Katrine Tokarski Boaventura foi orientada por Martino no mestrado e no doutorado de Comunicação da UnB, sendo os dois professores da Faculdade de Comunicação da UnB. Antônio Teixeira Barros também é professor da UnB, contudo não tem dedicado tanta ênfase em suas publicações à epistemologia no Campo da Comunicação. Com isso, nota-se que os fundamentos da interdisciplinaridade do Campo da Comunicação, na produção da Compós, se centralizam em autores ligados à UnB. Ou seja, os prismas sobre essa questão no contexto brasileiro têm se concentrado em um pequeno grupo da $\mathrm{UnB}$.

O Quadro 2 também apresenta as obras mais citadas nos artigos recuperados dos anais da Intercom sobre interdisciplinaridade, nos quais foram identificadas 36 obras referenciadas/citadas. Vale ressaltar que nos anais da Intercom foram recuperados 15 artigos com temática interdisciplinar (diferentemente da Compós, na qual foram identificados apenas três textos e seis citações na temática interdisciplinaridade).

Nota-se que não há uma obra que se destaque com muitas citações. Ou seja, com exceção da obra de Dencker, todas as obras foram referenciadas apenas uma vez. Percebe-se também que oito das 36 obras são de língua estrangeira. Uma dessas obras estrangeiras é do autor SCHMIDT, que apareceu nas referências dos artigos recuperados nos anais da Compós e da Intercom. Desses oito autores estrangeiros, apenas um é citado mais de uma vez. Ela é Julie Thompson Klein, pesquisadora da Wayne State University, que tem se dedicado a investigar o aumento da interdisciplinaridade nas instituições de ensino, especialmente sob o enfoque das mudanças curriculares.

Os autores que se destacam, com relação ao número de obras citadas, foram Ivani Fazenda (seis), Jean Piaget (três), Luiz C. Martino (quatro) e Julie Klein (duas). 
$\mathrm{Ou}$ seja, quatro autores representam quase a metade das obras referenciadas. Portanto, essa pode ser considerada a elite que fundamenta teoricamente os discursos sobre a interdisciplinaridade no Campo da Comunicação no Brasil.

Interessante observar que Ivani Fazenda é do campo da educação. Com várias publicações sobre a interdisciplinaridade, Fazenda (2012) elaborou uma organização retrospectiva dos estudos sobre interdisciplinaridade em três décadas: em 1970, ela procurou uma definição de interdisciplinaridade; já na década de 1980, ela tentou explicitar um método para a interdisciplinaridade; na de 1990, partiu para uma construção de uma teoria da interdisciplinaridade, à qual tem se dedicado atualmente.

De maneira diferente, Pombo (2003) considera praticamente impossível uma teoria única para um movimento fundamentado em vários campos. Como ressalta a autora, a palavra interdisciplinaridade tem sido aplicada em muitos contextos: epistemológico, pedagógico, midiático, empresarial e tecnológico. Esses contextos expandiram o uso do termo, dificultando a delimitação, a prática e o uso do conceito.

Dentre os autores mais citados (Jean Piaget, Luiz C. Martino e Julie Klein), ressalta-se que Piaget tem reconhecimento mundial de suas contribuições ao conhecimento, sendo reconhecido também pelas suas obras, que continuam a contribuir para a compreensão da interdisciplinaridade. Os autores Martino e Klein já foram mencionados anteriormente quanto às suas contribuições sobre interdisciplinaridade para o Campo da Comunicação, sobretudo no contexto brasileiro.

Vale ressaltar aqui, que em pesquisas realizadas com objetivos similares no campo da Ciência da Informação, o autor mais citado foi Hilton Japiassú, tendo sido citado por oito autores (CHALHUB; BENCHIMOL; GUERRA, 2013). Já nos resultados desta pesquisa o autor foi citado apenas uma vez, em sua obra denominada Interdisciplinaridade e patologia do saber (1976). Apesar de essa obra ser considerada uma das pioneiras no Brasil sobre interdisciplinaridade, é curioso observar que não se destacou na Comunicação como na Ciência da Informação. Além disso, outra obra do autor, $O$ sonho transdisciplinar e as razões da Filosofia 
(2006), citada no Campo da Ciência da Informação, não foi citada nos artigos científicos recuperados nos anais da Compós e da Intercom.

\section{Conclusões}

Esta pesquisa teve como objetivo central identificar as influências teóricas que fundamentam os debates sobre interdisciplinaridade no Campo da Comunicação no contexto brasileiro. São evidentes as limitações deste estudo, visto que não se analisou o conteúdo dos textos e os contextos das citações. Mas acredita-se que esta pesquisa pôde proporcionar reflexão sobre os fundamentos utilizados pelo Campo da Comunicação para fundamentar os artigos científicos que se enquadrem nessa temática.

Constatou-se que a produção científica na temática interdisciplinaridade no Campo da Comunicação não é tão expressiva e que os fundamentos teóricos, medidos pelas citações são restritos. Poucos são os artigos que trabalham com a questão interdisciplinar no Campo da Comunicação e poucos são os textos citados que fundamentam a interdisciplinaridade no campo. A fundamentação teórica sobre o tema se demonstrou frágil, sobretudo na produção da Compós, mas também o é, em certa medida, na Intercom.

Considerando a importância da interdisciplinaridade para o desenvolvimento da ciência na atualidade, sobretudo nos campos que emergem após a Segunda Guerra Mundial, entende-se ser fundamental a busca por aportes teóricos oriundos das mais diversas áreas e campos do conhecimento, como filosofia, educação, sociologia. Assim, haverá maior capacidade de se entender as potencialidades das disciplinas e de vislumbrar e viabilizar a atuação conjunta, aumentando a possibilidade de se resolver problemas complexos da sociedade contemporânea, difíceis de serem abordados de maneira puramente disciplinar. 


\section{Referências}

BICALHO, Lucinéia Maria. As relações interdisciplinares refletidas na literatura brasileira da informação, MG. 2009. 269 f. Tese (Doutorado em Ciência da Informação) - Programa Pós-Graduação em Ciência da Informação, Universidade Federal de Minas Gerais, Belo Horizonte, 2009. Disponível em:

<http://www.bibliotecadigital.ufmg.br/dspace/bitstream/handle/1843/ECID7UUQ69/teselucineia_versaodefinitiva.pdf?sequence=1>. Acesso em: 10 dez. 2015.

BOUGNOUX, Daniel. Introdução às ciências da comunicação. Bauru: Universidade do Sagrado Coração, 1999.

BOURDIEU, P. Os usos sociais da ciência: por uma sociologia do campo científico. São Paulo: Unesp, 2004.

BRAGA, José Luiz. Constituição do Campo da Comunicação. Verso e Reverso, São Leopoldo, v. 58, n. 15, p. 62-77, 2011. Disponível em:

<http://revistas.unisinos.br/index.php/versoereverso/article/view/924/147>. Acesso em: 20 jul. 2015.

CASANOVA, Pablo González. As novas ciências e as humanidades: da academia à política. São Paulo: Boitempo, 2006.

CHALHUB, Tânia; BENCHIMOL, Alegria; GUERRA, Claudia. A interdisciplinaridade na Ciência da Informação no Brasil: em que ombros se apóia? In: ENCONTRO NACIONAL DE PESQUISA EM CIÊNCIA DA INFORMAÇÃO, 14., 2013, Florianópolis. Anais... Florianópolis: ENANCIB, 2013.

CORREA, João Carlos. A Teoria da Comunicação de Alfred Schutz. Lisboa: Livros Horizonte, 2004.

FAZENDA, Ivani Catarina Arantes. Interdisciplinaridade: história, teoria e pesquisa. 15. ed. Campinas: Papirus, 2012.

GIL, Antônio Carlos. Métodos e técnicas de pesquisa social. 5. ed. São Paulo: Atlas, 1999.

JAPIASSÚ, Hilton. Interdisciplinaridade e patologia do saber. Rio de Janeiro: Imago, 1976.

LIDA COM O CAMPO. Origem Da Palavra - Site de Etimologia. Disponível em: <http://origemdapalavra.com.br/site/artigo/lida-com-o-campo/>. Acesso em: 4 jan. 2016. 
LOPES, Maria Immacolata Vassallo de. O Campo da Comunicação: reflexão sobre seu estatuto disciplinar. Revista USP, São Paulo, n. 48, p. 46-57, dez./fev. 20002001.

MARTIN-BARBERO, Jesús. Uma aventura epistemológica. Entrevistador: Maria Immacolata Vassallo de Lopes. MATRIZes, São Paulo, v. 2, n. 3, p. 143-162, jan./jun. 2009.

MARTINO, Luiz Claudio. Abordagens e representação do campo comunicacional. Comunicação Mídia e Consumo, São Paulo, v. 3, n. 8, p. 33-54, nov. 2006.

MATTELART, Armand; MATTELART, Michèle. História das teorias da comunicação. São Paulo: Loyola, 1999.

MELO, José Marques de. Comunicação social: teoria e pesquisa. 3. ed. Petrópolis: Vozes, 1973.

MINAYO, Maria Cecília S.; SANCHES, O. Quantitativo-qualitativo: oposição ou complementaridade? Caderno de Saúde Pública, Rio de Janeiro, v. 9, n. 3, p. 239$262,1993$.

MORIN, Edgar. A cabeça bem-feita: repensar a reforma, reformar o pensamento. 8. ed. Rio de Janeiro: Bertrand Brasil, 2003.

MORIN, Edgar. Ciência com consciência. 16. ed. Rio de Janeiro: Bertrand Brasil, 2014.

POMBO, Olga. Epistemologia da Interdisciplinaridade. In: SEMINÁRIO

INTERNACIONAL INTERDISCIPLINARIDADE, HUMANISMO, UNIVERSIDADE, 2003, Porto. Anais... Porto: Faculdade de Letras da Universidade do Porto, 2003.

RABAÇA, Carlos Alberto; BARBOSA, Gustavo. Dicionário de Comunicação. São Paulo: Ática, 1987.

REIS, Filipe. As relações (inter)disciplinares entre a Ciência da Informação e a Ciência da Comunicação: uma análise bibliométrica a partir de teses. 2014. 113 f. Trabalho de Conclusão de Curso (Graduação) - Curso de Biblioteconomia, Universidade Federal de Goiás, Goiânia, 2014.

SARACEVIC, Tefko. Ciência da informação: origem, evolução e ralações.

Perspectivas em Ciência da Informação, Belo Horizonte, v. 1, n. 1, p. 41-62, jan./jun. 1996. 
SIGNATES, Luiz. Epistemologia e comunicabilidade: as crises das ciências, ante a perspectiva da centralidade do conceito de comunicação. Comunicação \& Informação, Goiânia, v. 15, n. 2, p. 133-148, jul./dez. 2012.

SILVA, Juremir Machado da. Interfaces: Michel Maffesoli, teórico da comunicação. Revista FAMECOS, Porto Alegre, n. 25, p. 43-48, dez. 2004.

TEMER, Ana Carolina Rocha Pessoa; NERY, Vanda Cunha Albieri. Para entender as teorias da comunicação. 2. ed. Uberlândia: EDUFU, 2009.

VANZ, Samile Andréa de Souza; CAREGNATO, Sônia Elisa. Estudos de citação: uma ferramenta para entender a comunicação científica. Em Questão, Porto Alegre, v. 9, n. 2, p. 295-307, jul./dez. 2003.

\title{
The foundations of interdisciplinarity in the Communication Field: an analysis from Compós and Intercom papers
}

\begin{abstract}
There are frequent surveys with the interdisciplinary theme in the communication field, but little is known about the framework used for its theoretical foundation. Based on papers published in the annals of Compós and Intercom, between years 2005-2015, and using the bibliometric method of citation analysis, this research aimed to identify the theoretical pillars of interdisciplinarity in Brazilian Communication. Among the main results, it is highlighted, among the cited authors, that the theoretical foundations of the interdisciplinary field are restricted in the communication field, especially in the Compós papers. It was found that the authorship of the texts that support the interdisciplinary discourse in Compós articles is predominantly restricted to authors linked to only one Brazilian university and texts with authors of the communication field itself. There were no strong influences, as measured by citations to classical texts in the fields of philosophy, education, sociology, etc. Papers of Intercom, by contrast, there was the identification of reasoning on interdisciplinarity in other fields and other national and international authors, however, also in a limited fashion. We emphasize the importance of mobilizing authors to better theoretical foundation in communication studies, whether in interdisciplinary or opposite subject. It was found that in both cases, the reasoning of the speeches indicates weaknesses and short reach of theories.
\end{abstract}

Keywords: Communication field. Interdisciplinarity. Bibliometrics. Compós. Intercom.

\footnotetext{
${ }^{1}$ MAFFESOLI, Michel. O tempo das tribos: o declínio do individualismo nas sociedades de massa. 3. ed. Rio de janeiro: Forense Universitária, 1987.
} 
${ }^{2}$ Primitivamente, phármakon definia qualquer substância capaz de atuar no organismo animal, seja em sentido benéfico ou maléfico. Conforme Correa (2004), a pesquisa em comunicação surge quando esta se desnaturaliza. É quando ela se torna mediada por tecnologias que rompem espaço e tempo (mídias), tornando-se um problema de pesquisa com determinada força. A comunicação de massa se insere nesse contexto, desnaturalizando relações sociais, comprimindo espaço e tempo, levando pesquisadores à discussão sobre seus efeitos.

${ }^{3}$ De certo modo, a discussão sobre a mudança da cultura com o advento das tecnologias da comunicação se manifestou - e se manifesta - em todas as escolas e teorias propostas no campo. A teoria hipodérmica, por exemplo, aponta uma mídia que tem condições de modificar a cultura de um grupo social. Contudo, tal teoria desconsidera que os receptores têm uma "bagagem cultural" e uma organização que os permite resistir ou reinterpretar as mensagens midiáticas. Estudos posteriores apontaram a existência de líderes de opinião, agendamentos e outras relações entre a cultura de um grupo e seus modos de comunicar. A Teoria Crítica, por sua vez, aponta uma apropriação das manifestações culturais e sua transformação em produto, entre outras discussões. McLuhan e seus discípulos apontam como as tecnologias alteram as relações sociais, a percepção de si e a cultura de grupos. Outras teorias também apontam relações entre a cultura e a comunicação. Essa breve digressão, em algumas escolas, não procura fazer um apanhado teórico de toda a discussão das relações entre cultura e formas de comunicar. (KELLNER, 2001; TEMER; NERY, 2009; THOMPSON, 1998; entre outros).

Recebido em: 17/09/2016

Aceito em: 08/11/2016 